CLINICAL STUDY

\title{
Selective parathyroid venous sampling in patients with complicated hyperparathyroidism
}

\author{
C M Ogilvie ${ }^{1}$, P L Brown ${ }^{1}$, M Matson ${ }^{2}$, J Dacie ${ }^{2}$, R H Reznek ${ }^{2}$, K Britton ${ }^{3}$, R Carpenter ${ }^{4}$, D Berney ${ }^{5}$, W M Drake ${ }^{1}$, \\ P J Jenkins $^{1}$, S L Chew ${ }^{1}$ and J P Monson ${ }^{1}$ \\ Departments of ${ }^{1}$ Endocrinology, ${ }^{2}$ Radiology, ${ }^{3}$ Nuclear Medicine, ${ }^{4}$ Surgery and ${ }^{5}$ Pathology, St Bartholomew's Hospital, QMUL, London EC1A 7BE, UK \\ (Correspondence should be addressed to J P Monson; Email: Johnmonson@aol.com)
}

\begin{abstract}
Objective: The role of preoperative localisation of abnormal parathyroid glands remains controversial but is particularly relevant to the management of patients with recurrent or persistent hyperparathyroidism and familial syndromes. We report our experience of the use of selective parathyroid venous sampling (PVS) in the localisation of parathyroid disease in such patients. Design: We report a retrospective 10-year experience $(n=27)$ of the use of PVS in complicated primary hyperparathyroidism and contrast the use of PVS with neck ultrasound, magnetic resonance imaging (MRI), computed tomography (CT) and sestamibi imaging modalities.

Results: In 14 out of 25 patients who underwent surgery PVS results were completely concordant with surgical and histological findings and $88 \%$ of patients achieved post-operative cure. Out of 13 patients referred after previous failed surgery, 12 underwent further surgery which was curative in 9 . In total PVS yielded useful positive $(n=13)$ and/or negative information $(n=6)$ in 19 out of 25 patients undergoing surgery. Using histology as the gold standard, 59\% of PVS studies were entirely consistent with histology, as compared with $39 \%$ of ultrasound scans, $36 \%$ of sestamibi scans and $17 \%$ of MRI/CT scans.

Conclusions: PVS is a valuable adjunct to MRI/CT and sestamibi scanning in selected patients with complicated hyperparathyroidism when performed in an experienced unit.
\end{abstract}

European Journal of Endocrinology 155 813-821

\section{Introduction}

The current single curative treatment for primary hyperparathyroidism is surgery. The need for, and type of, preoperative localisation prior to parathyroid surgery remains controversial. Progress in localisation of parathyroid glands for necessary surgery is evolving continually. This subject is further complicated by patients with familial hyperparathyroid syndromes and patients who require re-operation for either recurrent disease or unsuccessful initial surgery. The technique of selective parathyroid venous sampling (PVS) has been reported previously in the setting of treatment for recurrent or persistent disease (1-4), if other investigations were inconclusive. Numbers reported were predictably small given the specific indications for this procedure. However, under these circumstances PVS provided positive predictive values of $80 \%$ (5), $75 \%$ (4) and 33\% (6). PVS has been described in the setting of work up for initial surgery in unselected patients and found to be non-contributory (6). We describe a single centre experience of the utility of PVS for the localisation and determination of function of overactive parathyroid glands in highly selected patients; those with either familial hyperparathyroid syndromes, failure of initial surgery or recurrent disease.

\section{Patients and methods}

This is a retrospective review of all adult patients who underwent PVS at our tertiary referral endocrine unit over a 10-year period. All records have been scrutinised $(n=27)$. All patients had primary hyperparathyroidism except for one who had tertiary hyperparathyroidism associated with renal failure. The diagnosis was made by history and confirmatory biochemistry. Our usual practice dictates that all such patients are investigated with a sestamibi scan, measure of gland function, as previously described (7) and anatomical scans, either a neck ultrasound, magnetic resonance imaging (MRI) or CT scan. A catheter was performed if patients had:

(a) Previous neck surgery in order to further define distorted anatomy.

(b) Known or newly diagnosed multiple endocrine neoplasia type 1 (MEN1) or familial hyperparathyroidism with the aim of defining ectopic disease.

(c) Evidence of non-concordant functional and anatomical imaging or non-diagnostic scans for further diagnostic information.

(d) Evidence of more than one area of involvement on sestamibi scanning and therefore suggestion of multiple gland disease and the possibility of ectopic disease. 
All catheters were performed by one out of two experienced interventional radiologists (M Matson, J Dacie), a single radiologist performed cross-sectional imaging (RH Rezneck) and surgery was undertaken by a single surgeon (R Carpenter).

A diagnosis of MEN1 was based on the presence of pituitary and/or pancreatic islet cell tumours in addition to hyperparathyroidism, and/or a family history of typical endocrinopathy in a patient with hyperparathyroidism, and/or a defined mutation in the menin gene.

Familial hypocalcuric hypercalcaemia was excluded due to the measurement of urine calcium clearance to creatinine clearance and this was $>0.03$ in all patients.

The pathology of the parathyroids was examined by an endocrine histopathologist. All glands were weighed on receipt and classified as adenomatous, hyperplastic or carcinoma based on macroscopic and histologic criteria. The diagnosis of adenoma was made on glands with an encapsulated tumour with a compressed rim of normal parathyroid. Any other excised glands had to be of normal or atrophic appearance. The adenomas were a mixture of chief cells and oxyphil cells, with the former predominating. Parathyroid hyperplasia was identified when multiple large glands with a multi-nodular enlargement were seen. The hyperplasia was usually made up of chief cells with occasional oxyphil cell clusters, no compressed rim of normal parathyroid was identified. The diagnosis of carcinoma was made on a constellation of features, including gland weight, the presence of fibrous bands, spindled tumour cells, mitotic figures, capsular invasion and vascular invasion. No cases of double adenoma or water clear hyperplasia were identified in this series.

A positive catheter was defined as a serum parathyroid hormone gradient of two times the peripheral measurement, as previously described (3). Peripheral serum parathyroid hormone concentrations were determined by taking the mean of measurements in the subclavian veins. This measure of positivity has been used in our audit. However, as is the nature of a retrospective review; in some cases the primary physician (WM Drake, PJ Jenkins, SL Chew and JP Monson) has used other definitions of positivity (e.g. 1.5 times the peripheral measurement) where this has occurred we have commented on this.

A combination of surgical and histological findings was used as the gold standard for analysis. Complete consistency had to be demonstrated for the localisation method to be analysed as positive, i.e. the localisation method had to demonstrate - right upper neck disease not just - right-sided disease.

Details of methodology are as follows:

\section{Radiological technique}

Venous access is obtained via the right femoral vein and seven French sheath inserted. Catheters are advanced under fluoroscopic screening into the relevant veins. Six
French-shaped catheters with one or two side holes at the distal end are used to facilitate sampling. A multipurpose catheter is often able to reach many of the desired sites; a headhunter catheter is sometimes useful to enter the left internal jugular vein, where a valve can sometimes be obstructive. A cobra catheter is useful for accessing the superior and middle thyroid veins and the left superior intercostal vein and thymic mediastinal vein. This last vein is often the most technically challenging with a small ostium opening into the left innominate vein. Even when entered, it is sometimes impossible to aspirate blood. In these cases in which the catheter obstructs the ostium of a small vein, we have found it useful to allow blood to slowly drip from the end of the catheter or to use a gentle siphoning technique with tubing attached to the end of the catheter placed below the level of the patient. Using these techniques we have not found the need to routinely use coaxial microcatheters.

\section{Sestamibi}

Approximately $20 \mathrm{MBq}{ }^{123} \mathrm{I}$ were injected intravenously followed by an injection of $600 \mathrm{MBq}{ }^{99 \mathrm{~m}} \mathrm{Tc}-\mathrm{Ses}-$ taMIBI 60 min later. A zoomed 20-min dual isotope dynamic acquisition was performed using a $256 \times 256$ matrix and asymmetric energy windows of 126-147 and $151-174 \mathrm{keV}$ for ${ }^{99 \mathrm{~m}} \mathrm{Tc}$ and ${ }^{123} \mathrm{I}$ respectively. The dynamic images were corrected for motion when necessary. Dynamic image frames were then summed to create static images. The static images were then compared using a statistical technique whereby the ${ }^{123}$ I image was used as a template of the thyroid and any difference between corresponding pairs of pixels in the ${ }^{99 \mathrm{~m}} \mathrm{Tc}$-SestaMIBI and ${ }^{123} \mathrm{I}$ images were assessed as to whether they constituted a significant difference in relation to the global regression between all the corresponding pixel pairs under consideration. Such differences were assigned p-values and displayed as images. This method is analogous to image subtraction but designed to be of a more objective nature was used to compare ${ }^{123} \mathrm{I}$ and ${ }^{99 \mathrm{~m}} \mathrm{Tc}$-SestaMIBI static images. An additional static acquisition approximately 2-h post ${ }^{99 \mathrm{~m}} \mathrm{Tc}$-SestaMIBI injection was also carried out as a washout image in order to assess any areas of retained tracer activity.

\section{Ultrasound}

Ultrasound scans were performed using an Acuson Sequoia 512 ultrasound system (Siemens, Mountain View, CA, USA). All scans were performed with a 15 L8W probe with a $52 \mathrm{~mm}$ footprint. Scans were performed routinely both in the longitudinal and in the transverse planes, where a parathyroid mass was identified, it was measured using electronic calipers. The normal parathyroids, where possible, were also measured. 


\section{CT}

Scans were performed using a GE Lightspeed Ultra 8-slice multidetector scanner or a GE High Speed ZX/i (General Electric, Milwaukee, WI, USA). Scans were performed at $2.5 \mathrm{~mm}$ space intervals, from the base of the skull to the carina, both before and after intravenous injection of contrast medium. Contrast medium of $100 \mathrm{ml}$ was injected at $3 \mathrm{ml} / \mathrm{s}$ and the scans commenced at $40 \mathrm{~s}$ following the onset of contrast medium injection.

\section{MRI}

MRI was performed using a $1.5 \mathrm{~T}$ superconductive magnet (Signa, General Electric Medical Systems, 1996). Sequences included an axial T1-weighted from the base of the skull to the carina (TR 500-540, TE 8-9, slice width $4 \mathrm{~mm}$, interslice gap 0-2 $\mathrm{mm}$, number of acquisitions 2, matrix $256 \times 256$ ) and T2-weighted axial (TR 3333-7508, TE 80-90 EF, ETL 8, slice width 3-4 mm with an interslice gap of $0-1 \mathrm{~mm}$, number of acquisitions 2, matrix $256 \times 256-512 \times 512$ ). This was supplemented by fat-saturated T2-weighted sequences together with coronal Short Tau Inversion Recovery sequences. Intravenous contrast medium was not administered.

\section{PTH assay}

Our parathyroid hormone (PTH) assay is intact PTH (DPC IMMULITE 2500). It is specific for intact PTH 184 but has $40 \%$ cross-reactivity with fragment 7-84. Precision across the range is approximately $8 \%$.

\section{Results}

Patient outcomes are summarised in Table 1. Although PVS is more invasive than anatomical scanning, no complications of the procedure were observed.

\section{Overall picture}

A total of 27 patients underwent PVS. Subsequent surgical cure was defined as persisting normocalcaemia or requirement for $1 \alpha$-hydroxycholecalciferol therapy (i.e. hypoparathyroid state) during a mean and a median of three patient years of follow-up. Thirteen patients were referred having undergone previous neck surgery; of these, nine were cured after repeat surgery subsequent to localising investigations, including PVS. In the 25 patients who underwent operation, 14 PVS (59\%) were completely consistent with surgical and histological findings. However, in total 19 (76\%) PVS were considered by the supervising physician to contribute valuable positive $(n=13)$ or negative $(n=6)$ information. Surgical cure was achieved in 22 out of 25 patients who underwent surgery giving a cure rate of $88 \%$.

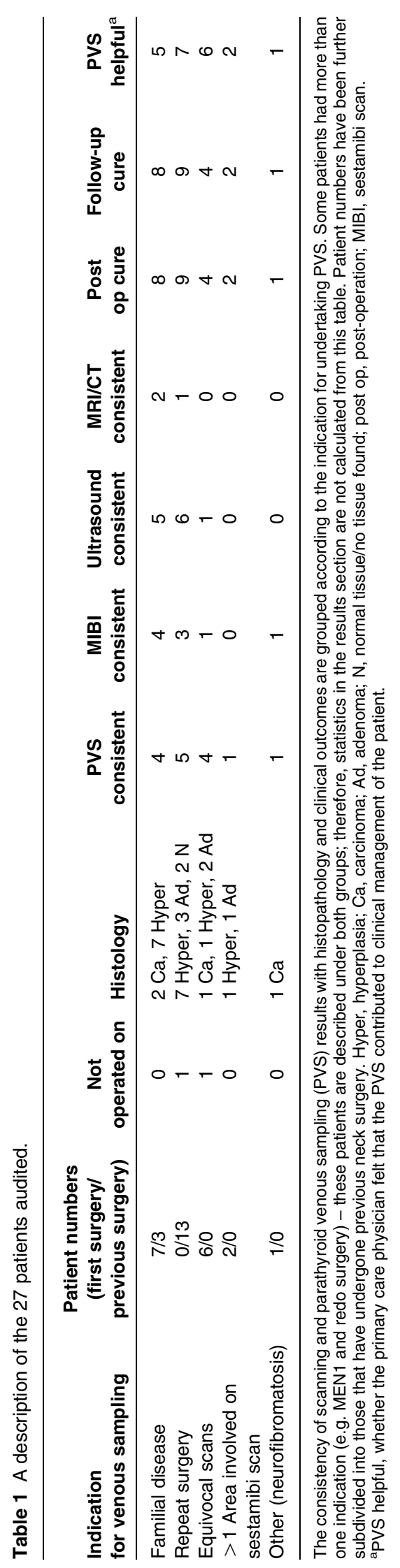

www.eje-online.org 
Using histological findings as the gold standard, PVS had a positive predictive value (PPV) of $81 \%$ (using a diagnostic threshold of two times the peripheral samples). The positive predictive values for ultrasound scanning, sestamibi scanning and MRI/CT were 73, 72 and $57 \%$ respectively. It should be recognised that as one of the criteria for performing PVS was equivocal or non-conclusive diagnostic studies, by definition the positive predictive value of these other studies would be expected to be lower than in an unselected population of patients with hyperparathyroidism. Results were further analysed to determine the optimum diagnostic gradient to use to determine a positive PVS. At ratios of $1.5,2.5$ and $3 \times$ peripheral sample, the PPV is $72 \%$; for $2.5 \times$ is $75 \%$ and $3 \times$ is $83 \%$ respectively.

Eight patients (35\%) had a diagnosis of MEN1 made prior to surgery and one patient had familial hyperparathyroidism. PVS was performed to determine the presence of ectopic parathyroid tissue and this was evident in five out of eight MEN1 patients who underwent surgery. The routine surgical approach in familial hyperparathyroid disease is total neck exploration and either total or 3.5 gland clearance. Without the information derived from PVS in these patients 63\% would not have been cured with the first procedure as their mediastinal disease would not have been identified.

Eight PVS were negative, four because of technical failure to cannulate the thymic mediastinal vein. Therefore, four gave a false negative result. Three PVS gave a false positive result; patients 9,11 and 20. Two of these patients (9 and 20) were not rendered normocalcaemic by surgery and hence it is possible that adenomatous tissue in these areas was not found at surgery. Patient 11 was falsely positive in the superior vena cava, which could indicate aberrant venous drainage from abnormal parathyroid tissue.

The magnitude of the ratio between the peripheral samples and the highest sample measured can predict the accuracy of PVS findings. If this ratio is $>3$, then all of our PVS findings were consistent with findings at surgery. A total of 53 patient years of follow-up has been achieved on those subjects who underwent operation.

\section{Details of individual patients}

These are described in Tables 1 and 2. In patient 1 PVS results were highly suggestive; serum parathyroid hormone in the left innominate vein sample was $102 \mathrm{pmol} / \mathrm{l}$, the next highest sample was $28 \mathrm{pmol} / \mathrm{l}$ from the right atrium. Given the high likelihood of recurrence of parathyroid disease in patients with MEN1 (8) hypercalcaemia may recur.

Patient 2 had a negative PVS by our criteria. However, peripheral arm PTH samples averaged $38 \mathrm{pmol} / \mathrm{l}$. Whilst none of the PVS samples were higher than $76 \mathrm{pmol} / \mathrm{l}$ the superior vena cava sample was $52 \mathrm{pmol} / \mathrm{l}$ and right atrium $54 \mathrm{pmol} / \mathrm{l}$. Normally both of these samples would be affected by dilution, meaning that both results should be similar to peripheral samples. A possible ectopic adenoma was seen on sestamibi scanning; these two pieces of information prompted advice to the surgeon that mediastinal exploration be undertaken.

Patient 3 was referred from another centre with the clinical problem of a mediastinal mass, a skull base lesion and primary hyperparathyroidism. The skull base mass was diagnosed as an invasive prolactinoma. PVS was positive in multiple areas. Initial neck exploration revealed a right-sided parathyroid mass with histological confirmation of parathyroid carcinoma; neck clearance was performed but the patient remained hypercalcaemic. Review of the catheter data demonstrated that the thymic mediastinal vein and superior vena cava (SVC) had a gradient of 1.5 over peripheral concentrations. Due to dilution effect from venous drainage these areas should normally demonstrate parathyroid hormone concentrations similar to periphery. Therefore, surgical exploration of the mediastinum was undertaken and revealed a retro-oesophageal parathyroid lesion with histological characteristics of carcinoma. This patient remains normocalcaemic on $1 \alpha$-hydroxycholecalciferol therapy 2 years later.

In patient 4 multiple gland involvement was suggested by both sestamibi and ultrasound scanning. PVS failed to catheterise the mediastinal vein. In the absence of imaging evidence of mediastinal disease the surgeon did not explore the mediastinum.

In patients 5, 6 and 8, the presence of multi-nodular goitre meant that all other scans were equivocal. This is a recognised limitation of sestamibi scanning (9).

In patient 7 sestamibi and neck ultrasound both showed left-sided disease. However, sestamibi suggested both upper and lower parathyroid disease. As this was the patient's fourth neck operation (two for parathyroid disease; one removing an adenoma and one re-exploration negative; and one for papillary thyroid carcinoma) and the patient had previous neck radiotherapy, surgery was limited by necessity and all possible information was considered helpful. PVS also localised disease to the left side and two parathyroid adenomas were removed. The patient remains normocalcaemic on $1 \alpha$-hydroxycholecalciferol 8 years later.

Patient 9 had undergone two previous neck operations, at which normal parathyroid glands were removed, and remained hypercalcaemic. At PVS the left superior thyroid, middle thyroid, right low thyroid and the thymic mediastinal veins could not be cannulated. However, PVS was positive in the left inferior thyroid and the left innominate veins. Unfortunately surgical exploration was negative. The patient suffered a myocardial infarction perioperatively and was unfit for further surgery.

Patient 10 had MEN1 and had undergone noncurative surgery in 1994. Ultrasound suggested two left-sided parathyroid lesions; sestamibi scanning 
Table 2 Individual patient details illustrating operative findings, parathyroid venous sampling (PVS) and imaging results.

\begin{tabular}{|c|c|c|c|c|c|c|c|c|c|}
\hline Subject & $\begin{array}{l}\text { Gender/year } \\
\text { of birth }\end{array}$ & $\begin{array}{l}\text { Peripheral PTH } \\
\text { level }(\mathrm{pmol} / \mathrm{l})\end{array}$ & Histology & Sestamibi & USS & MRI/CT & PVS-2 $\times$ & MEN1 & Last available calcium \\
\hline 1 & $\mathrm{M} / 1971$ & 20.3 & Carcinoma, left side & $\mathrm{LL}$ and $\mathrm{RU}$ & LL & Not done & $+\mathrm{L}$ innominate & Yes & $2.07 \mathrm{mmol} / \mathrm{l} 2004$ \\
\hline 2 & $F / 1939$ & 38.1 & $\begin{array}{l}\text { Hyperplasia + mediastinal } \\
\text { ectopic }\end{array}$ & $\begin{array}{l}\mathrm{R} \text { lobe adenoma }+ \\
\text { retrosternal }\end{array}$ & $\mathrm{RL}$ & $\begin{array}{l}\text { Med disease at } \\
\text { aortic arch }\end{array}$ & Negative & Yes & $2.39 \mathrm{mmol} / \mathrm{l} 2004$ \\
\hline 3 & $F / 1934$ & 40 & $\begin{array}{l}\text { Carcinoma, multiple } \\
\text { areas, retrosternal } \\
\text { extension }\end{array}$ & $\mathrm{RL}$ & Not done & LU, LL & $+\mathrm{RU}, \mathrm{RL}$ & Yes & $2.28 \mathrm{mmol} / \mathrm{l}$ \\
\hline 4 & $F / 1946$ & 23.9 & $\begin{array}{l}4 \text { Gland hyperplasia neck } \\
\text { not explored }\end{array}$ & RL, LL, L middle & $\begin{array}{l}\text { LL, } R \text { middle, } \\
\text { posterior to } \\
\text { thyroid }\end{array}$ & LL, RU & Negative & Yes & $2.21 \mathrm{mmol} / \mathrm{l}$ \\
\hline 5 & $F / 1937$ & 76.9 & $\begin{array}{l}\mathrm{R} \text { Carcinoma }+4 \text { gland } \\
\text { hyperplasia }\end{array}$ & Equivocal, MNG & $\begin{array}{l}\text { MNG, no para- } \\
\text { thyroid seen }\end{array}$ & Equivocal & +RU, LU, LL & No & $2.07 \mathrm{mmol} / \mathrm{l}$ \\
\hline 6 & $F / 1941$ & 14.4 & $\begin{array}{l}\text { No operation, patient } \\
\text { overseas }\end{array}$ & Equivocal, MNG & Not done & Negative & $+\mathrm{RL}$ & No & $\mathrm{N} / \mathrm{A}$ \\
\hline 7 & $F / 1928$ & 42.5 & $\begin{array}{l}1 \text { Adenoma removed } L \\
\text { side }\end{array}$ & LU, LL & LU & Not done & +L innominate & Not looked for & No calcium available \\
\hline 8 & $F / 1946$ & 37.5 & $\begin{array}{l}\text { Left side removed } \\
\text { hyperplasia }\end{array}$ & Equivocal & $\begin{array}{l}\text { No parathyroid } \\
\text { localised }\end{array}$ & Inconclusive & +LL, LU, SVC & No & $2.23 \mathrm{mmol} / \mathrm{l}$ \\
\hline 9 & $M / 1934$ & 5 & $\begin{array}{l}\text { No adenoma found at OT } \\
\text { nor on histology }\end{array}$ & LU & Not done & Not done & LL & No & $2.66 \mathrm{mmol} / \mathrm{l}$ \\
\hline 10 & $F / 1971$ & 9.9 & $\begin{array}{l}\text { Hyperplasia, } L \text { side } \\
\text { removed }\end{array}$ & LU & $\begin{array}{l}\mathrm{L} \text { middle } 2 \text { ade- } \\
\text { nomas }\end{array}$ & Not done & +LL, LU, SVC & Yes & $2.26 \mathrm{mmo} / \mathrm{l}$ \\
\hline 11 & $F / 1983$ & 11.7 & $\begin{array}{l}\text { Hyperplasia, L side } \\
\text { removed }\end{array}$ & LL & LL & LL & + SVC & No & $2.29 \mathrm{mmol} / \mathrm{l}$ \\
\hline 12 & $F / 1925$ & 16.9 & Hyperplasia + ectopic & Med adenoma & Not done & Equivocal & +LL, med, SVC & No & $2.27 \mathrm{mmol} / \mathrm{l}$ \\
\hline 13 & $F / 1950$ & 24.3 & $\begin{array}{l}\text { R Carcinoma, L not } \\
\text { explored }\end{array}$ & $\mathrm{R}$ middle and $\mathrm{RL}$ & $\begin{array}{l}\mathrm{R} \text { middle }+\mathrm{L} \\
\text { middle neuro- } \\
\text { fibroma }\end{array}$ & $\begin{array}{l}\mathrm{RL}, \mathrm{L} \text { middle } \\
\quad \text { equivocal }\end{array}$ & $+\mathrm{RU}, \mathrm{RL}, \mathrm{SVC}$ & No & $2.32 \mathrm{mmol} / \mathrm{l}$ \\
\hline 14 & $F / 1959$ & 28.8 & $\begin{array}{l}\text { Hyperplasia, L side } \\
\text { removed }\end{array}$ & $\mathrm{L}$ adenoma + med & LU & Not done & $+\mathrm{LL}$ & No & $2.44 \mathrm{mmol} / \mathrm{l}$ \\
\hline 15 & $F / 1968$ & 15.2 & $\begin{array}{l}\text { LL adenoma, } 2 \text { normal } \\
\text { glands }\end{array}$ & Negative & LL & Not done & $+\mathrm{LL}$ & Not looked for & $2.11 \mathrm{mmol} / \mathrm{l}$ \\
\hline 16 & $\mathrm{M} / 1947$ & 16.6 & $\begin{array}{l}\text { Hyperplasia, } 4^{\text {ti i }} \text { gland } \\
\text { extends into } \\
\text { mediastinum }\end{array}$ & 4 Gland hyperplasia & LU, R posterior & Negative & Negative & Yes & $1.99 \mathrm{mmol} / \mathrm{l}$ \\
\hline 17 & $F / 1954$ & 8.9 & $\mathrm{R}$ hyperplasia & $\mathrm{RL}$ & $\mathrm{RL}$ & $\mathrm{RL}$ & Negative & Yes & $2.61 \mathrm{mmol} / \mathrm{l}$ \\
\hline 18 & M/1959 & 18.1 & $\mathrm{R}$ hyperplasia & $\mathrm{R}$ mid + LL & RL lobe & Not done & $+\mathrm{R}$ innominate & Yes & $2.39 \mathrm{mmol} / \mathrm{l}$ \\
\hline 19 & $F / 1949$ & 7.1 & 4 Gland hyperplasia & $\mathrm{LL}$ and $\mathrm{RU}$ & LL & Not done & Negative & Familia IHPTH & $2.21 \mathrm{mmol} / \mathrm{l}$ \\
\hline 20 & $F / 1947$ & 18 & $\begin{array}{l}\text { Normal gland from med, } \\
\text { previous hyperplasia }\end{array}$ & $\begin{array}{l}\text { Equivocal positivity in } \\
\text { med }\end{array}$ & LL, LU pole & LU, LL & $+\mathrm{LL}$ and $\mathrm{RA}$ & No & $2.67 \mathrm{mmol} / \mathrm{l}$ \\
\hline 21 & M/1969 & 9.5 & $\begin{array}{l}\text { Med adenoma, } 1 \\
\text { adenoma previously } \\
\text { removed }\end{array}$ & + Thyroid isthmus & LL lobe & $\begin{array}{l}\text { LL lobe, } \\
\text { equivocal }\end{array}$ & $+\mathrm{RA}$ & No & Not available \\
\hline 22 & M/1947 & 130 & L hyperplasia & LL & Not done & $\begin{array}{l}\text { Left side and } \\
\text { med disease }\end{array}$ & Negative & $\begin{array}{l}\text { Not looked for } \\
\text { tertiary } \\
\text { disease }\end{array}$ & $2.25 \mathrm{mmol} / \mathrm{l}$ \\
\hline 23 & $F / 1963$ & 12 & $\mathrm{~L}$ adenoma, $\mathrm{LL}$ gland & LL & LL & Left adenoma & Negative & No & $2.33 \mathrm{~mol} / \mathrm{l}$ \\
\hline
\end{tabular}


located one lesion. PVS also suggested two left-sided lesions and absence of mediastinal disease.

In patient 11 PVS ruled out the presence of mediastinal disease and therefore was contributory, but was categorised as unhelpful as it was only positive in the SVC and not consistent with surgical findings (a false positive PVS study).

Patient 12 required a second operation. Sestamibi scan prior to the first operation was negative for mediastinal disease. However, it demonstrated multiple gland involvement and therefore, by our criteria, this patient would have been a candidate for PVS. PVS performed prior to the second operation showed mediastinal and right-sided secretion of PTH. A second sestamibi at this stage also indicated mediastinal disease.

Patient 13 had neurofibromatosis, making crosssectional imaging and surgical findings difficult to interpret and hence functional localisation was indicated. PVS was convincing of right-sided disease (Fig. 1) and in view of concordance with the sestamibi scan the surgeon did not explore the left side of the neck.

Patient 14 required repeat surgery for persistent disease. PVS excluded mediastinal disease, which had been suggested by sestamibi scanning and was consistent with ultrasound findings.

Patient 15 had a biochemical diagnosis of hyperparathyroidism and was symptomatic of renal calculi. Localisation of a single parathyroid lesion was evident on ultrasound. However, sestamibi scan was negative. PVS was indicative of a single parathyroid lesion and this was confirmed at surgery.

Patient 16 had MEN1 and four gland hyperplasia on histology. All scanning and PVS gave a negative result, but PVS excluded the presence of mediastinal disease and this patient remains normocalcaemic after 2 years.

Patient 17 had MEN1 and required a repeat operation (three previous neck operations). Ultrasound, sestamibi and MRI scan all suggested right-sided lower disease but PVS was negative. A hyperplastic gland was removed from the right side.

Patient 18 had undergone three previous operations. Sestamibi scan suggested two right-sided parathyroid lesions and these were confirmed at surgery. Ultrasound and PVS had indicated a single right-sided lesion.

Patient 19 has familial hyperparathyroidism and PVS failed to cannulate the mediastinal vein or show a gradient. Surgical findings demonstrate four gland hyperplasia.

Patient 20 had undergone one previous operation. Sestamibi scan and MRI suggested mediastinal disease and PVS was positive in the right atrium. At surgery a normal parathyroid gland was removed from the mediastinum; exploration of left side of the neck was negative. The patient declined further surgery.

Patient 21 had two previous adenomas removed. PVS was the only investigation that demonstrated mediastinal disease and the patient remains normocalcaemic on $1 \alpha$-hydroxycholecalciferol 4 years later. 


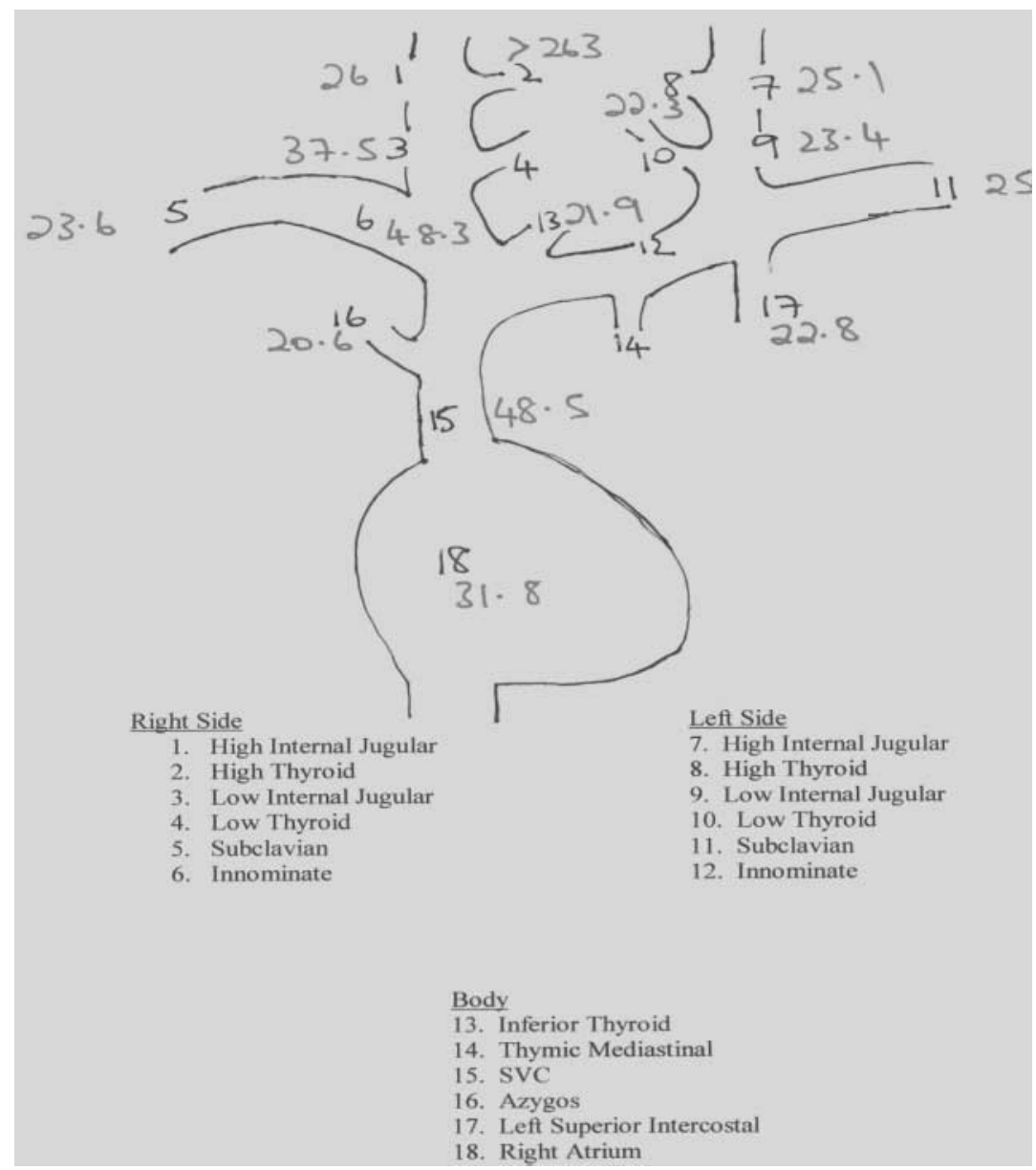

Figure $1 \mathrm{~A}$ representative parathyroid venous sampling catheter map (patient 13). The map demonstrates anatomical sites numbered 1-18 and serum parathyroid hormone concentrations $(\mathrm{pmol} / \mathrm{l})$ at each site. The average of the subclavian veins is 24 ; a gradient of $2 \times$ this is $>48$. This is clearly reached in the right high thyroid and is suggested in the right innominate and superior vena cava. The patient had a right sided parathyroid carcinoma removed from her neck.
Patient 22 had end stage renal failure and tertiary hyperparathyroidism. PVS was negative by our criteria but the left innominate vein sample $(203 \mathrm{pmol} / \mathrm{l})$ was clearly elevated over the next lowest sample (143 pmol/l) and this was consistent with surgical localisation of disease.

Patient 23 required reoperation and PVS was the only study that was negative; all other investigations pointed to the left-sided adenoma that was removed at surgery.

PVS in patient 24 was performed because of equivocal ultrasound and sestamibi scans and negative MRI. PVS and sestamibi both indicate mediastinal disease, and surgery is planned.

Patient 25 had a right lower gland adenoma localised by PVS.

In patient 26, analysis of PVS using a gradient of $2 \times$ the peripheral parathyroid hormone measurements demonstrated involvement of both the right upper and lower parathyroids. When a gradient of $1.5 \times$ peripheral measurements was used, the PVS was the only investigation to conclusively demonstrate four gland disease.

In patient 27 sestamibi and PVS supported surgical findings.

\section{Discussion}

Single parathyroid adenomas account for approximately $85 \%$ of all cases of primary hyperparathyroidism (10). Multiple gland involvement and parathyroid carcinoma are much rarer conditions. However, because re-operation exposes patients to further risks and increases surgical challenges it is important that we provide maximum localisation information to allow the first operation the highest likelihood of cure. Cost analysis shows that the financial costs for re-operation can be up to three times as much as initial costs (11). Complicated hyperparathyroidism, as defined in the present study, should not be forgotten in the drive for minimally invasive parathyroid surgery. Clearly, minimally invasive surgery is inappropriate for such patients (12).

\section{Repeat operations}

Patients who have persisting hypercalcaemia postoperatively have a much higher likelihood of having multiple adenomas, hyperplasia or carcinoma (13). Reasons for persisting hypercalcaemia post-operatively include missed ectopic disease (3) and either no or 
inaccurate preoperative imaging. Traditional imaging has been shown to have limitations when overactive parathyroid glands are small, there is multiple parathyroid gland involvement or when thyroid disease is coexistent (14). Ultrasound is operator-dependent and is limited in detecting tissue behind bone. Previously, MRI has been the investigation of choice for mediastinal disease (14). However, the information from MRI is limited to anatomical considerations. Undescended adenomas have been reported as reasons for persisting hypercalcaemia post-operatively (5); the incidence of such lesions is reported to be $7 \%$ and none were found in our series. However, PVS found $80 \%$ of these adenomas in this single study (5). Clearly, it is desirable that the first operation is curative in the context of both patient safety and longer term health, and PVS offers further opportunity for diagnostic information.

\section{Familial hyperparathyroidism}

Familial hyperparathyroid syndromes include MEN1 and 2A, hyperparathyroidism-jaw tumour syndrome and familial isolated hyperparathyroidism. The diagnosis of any of these syndromes will alter patient management.

Approximately $20 \%$ of patients with multiple gland involvement will have a hereditary syndrome, such as MEN1 (10). Thirty percent of MEN1 patients will have an ectopic parathyroid gland (8); in our study this has reached $60 \%$. Full neck exploration is necessary in these patients; mediastinal exploration would only be undertaken, should preoperative investigations suggest mediastinal disease and preoperative PVS is an effective way of determining the presence of such disease. Other reviews have called for MEN1 screening only in patients who have a family history or are symptomatic from other endocrinopathies (15). However, given that 30\% of our patients had MEN1 we believe it is important to screen patients who present with multiple parathyroid gland involvement for MEN1. PVS has been previously described as initial work up for MEN1 patients by the $\mathrm{NIH}$ group (16). Bilateral disease but no mediastinal disease was found in four out of five subjects investigated using PVS $63 \%$ of our subjects investigated with PVS had mediastinal disease.

A prospective review of preoperative localisation (17) demonstrated a sensitivity of $95 \%$ for sestamibi scanning in cases of single adenoma but sensitivity decreased to $25 \%$ in multiple gland disease. A further retrospective review described a sensitivity of $62 \%$ using sestamibi in patients with multiple gland disease (18). Intraoperative PTH monitoring may be misleading in over $50 \%$ of patients with multiple gland involvement (17). The presence of mediastinal disease is an important clinical question and investigations other than PVS are not always reliable in this area.

\section{PVS}

In our series, thirteen of the PVS studies yielded information not available from any of the other modalities of localisation. None of our patients experienced any complications from the PVS study. Previously PVS has only been used in the setting of persistent hyperparathyroidism. However, when there is suggestion of multiple gland disease it is appropriate to perform this procedure preoperatively to increase the likelihood of achieving cure by a single operation.

\section{Conclusion}

We are fortunate in having access to a highly experienced interventional radiologist who is performing endocrine catheters on a weekly basis. This is an operator-dependent investigation and experience with PVS is mandatory to achieve successful results. For complicated hyperparathyroid patients (i.e. those with familial syndromes, previous failed surgery, coexistent thyroid pathology or evidence of possible multiple gland involvement) full perioperative planning and open bilateral neck exploration with or without mediastinal exploration is required. Avoiding the need for re-operation is desirable. PVS is a valuable adjunct to MRI/CT and sestamibi in such patients.

\section{Acknowledgements}

We are grateful to our research nurses, Kathy Maher, Francess Fode, Leonila Kalingag and Mary O'SullivanHawketts, for their assistance in the selective venous catheter studies and to the Department of Clinical Biochemistry, Barts and The London NHS Trust for the parathyroid hormone assays.

\section{References}

1 Chaffanjon PC, Voirin D, Vasdev A, Chabre O \& Kenyon NM. Selective venous sampling in recurrent and persistent hyperparathyroidism: indication, technique and results. World Journal of Surgery 200428 958-961.

2 Estella E, Leong MS, Bennett I, Hartely L, Wetzig N, Archibald CA, Harper JS \& Cuneo RC. Parathyroid hormone venous sampling prior to reoperation for primary hyperparathyroidism. ANZ Journal of Surgery 200373 800-805.

3 Sugg SL, Fraker DL \& Alexander R. Prospective evaluation of selective venous sampling for parathyroid hormone concentration in patients undergoing reoperations for primary hyperparathyroidism. Surgery $19931141004-1010$.

4 Jones JJ, Brunaud L, Dowd CF, Duh OY, Morita E \& Clark OH. Accuracy of selective venous sampling for intact parathyroid hormone in difficult patients with recurrent or persistent hyperparathyroidism. Surgery 2002132 944-950.

5 Billingsley KG, Fraker DL, Doppman JL, Norton JA, Shawker TH, Skarulis MC, Marx SJ, Spiegel AM \& Alexander HR. Localization 
and operative management of undescended parathyroid adenomas in patients with persistent primary hyperparathyroidism. Surgery $1994116982-990$.

6 Pattou F, Oudar C, Hugho D, Racadot A, Carnaille B \& Proye C. Localisation of abnormal parathyroid glands with jugular sampling for parathyroid hormone and subtraction scanning with sestamibi or tetrofosmine. Australian and New Zealand Journal of Surgery $1998 \mathbf{6 8} 108-111$.

7 Johnston LB, Carroll MJ, Britton KE, Lowe DG, Shand W, Besser GM \& Grossman AB. The accuracy of parathyroid gland localisation in primary hyperparathyroidism using sestamibi radionuclide imaging. Journal of Clinical Endocrinology and Metabolism 1996 81 346-352.

8 Arnalsteen LC, Alesian PF, Quiereux JL, Farrel SG, Patten FN, Carnaille BM, Cardot-Bauters CM, Werneau JL \& Proye CA. Longterm results of less than total parathyroidectomy for hyperparathyroidism in multiple endocrine neoplasia type 1. Surgery 2002 132 1119-1125.

9 Krausz Y, Shiloni E \& Bocher M. Diagnostic dilemmas in parathyroid scintigraphy. Clinical Nuclear Medicine 200126 997-1001.

10 Marx SJ. Hyperparathyroid and hypoparathyroid disorders. New England Journal of Medicine 2000 343 1863-1875.

11 Doherty GM, Weber B \& Norton JA. Cost of unsuccessful surgery for primary hyperparathyroidism. Surgery $1994116954-958$.

12 Schachter PP, Issa N, Shimonov M, Czerniak A \& Lorberboyam M. Early, postinjection MIBI-SPECT as the only preoperative localizing study for minimally invasive parathyroidectomy. Archives of Surgery $2004139433-437$.
13 Weber CJ, Sewell CW \& McGarity WC. Persistent and recurrent sporadic primary hyperparathyroidism: histopathology, complications and results of reoperation. Surgery 1994116 991-998.

14 Wakamatsu H, Noguchi S, Yamashite H, Yamashite H, Tamura S, Jinnouchi S, Naganachi S \& Futami S. Technetium-99 tetrofosmin for parathyroid scintigraphy: a direct comparison with ${ }^{99} \mathrm{~m}$ Tc-MIBI, ${ }^{201} \mathrm{TI}, \mathrm{MRI}$ and US. European Journal of Nuclear Medicine 200128 1817-1827.

15 Muhr C, Ljunghall S, Akerstrom G, Palmer M, Bergstrom K, Enoksoon P, Lundqvist G \& Wide L. Screening for multiple endocrine neoplasia syndrome (Type 1) in patients with primary hyperparathryoidism. Clinical Endocrinology 198420 153-162.

16 Marx SJ, Powell D, Shimkin PM, Wells SA, Ketcham AJ, McGuigan JE, Bilezikian JP \& Aurbach GD. Familial hyperparathyroidism: mild hypercalcaemia in at least nine members of a kindred. Annals of Internal Medicine $1973 \mathbf{7 8} 371-377$.

17 Perrier ND, Ituarte PH \& Morita E. Parathyroid surgery: separating promise from reality. Journal of Clinical Endocrinology and Metabolism 200287 1024-1029.

18 Thompson GB, Mullan BP, Grant CS, Gorman CA, van Heerden JA, O'Conner MK, Goellner JR \& Ilstrup DM. Parathyroid imaging with technetium-99m-sestamibi: an initial institutional experience. Surgery $1994116966-972$.

Received 22 June 2006

Accepted 28 September 2006 